\title{
Modelling of Immobilised Enzyme Biocatalytic Membrane Reactor Performance
}

Ryne du Preez ${ }^{a}$, Kim G Clarke $^{a}$, Linda H Callanan ${ }^{a}$ and Stephanie G Burton ${ }^{b}$

${ }^{a}$ Department of Process Engineering, Stellenbosch University, Private Bag X1, Stellenbosch 7602, South Africa

${ }^{b}$ Department of Chemical Engineering, University of Cape Town, Private Bag X3, Rondebosch 7701, South Africa ${ }^{1}$

Corresponding author: $\quad$ Professor Kim G Clarke

Tel: +27218084421

kclarke@sun.ac.za

\begin{abstract}
Immobilised enzyme-catalysed conversions frequently provide specific advantages of selectivity over chemical conversions and further, facilitate continuous operation through biocatalyst retention and reuse. This study focuses on the development and modelling of an enzyme-catalysed continuous immobilised enzyme biocatalytic membrane reactor (BMR). The conversion of the amidase-catalysed lactamide to lactic acid process was used as an industrially representative system with which to evaluate the process performance of the BMR.

The model was developed from unsteady state differential mass balances incorporating a second order enzyme decay. This model was validated from empirically determined conversions in dual experiments using 80 and $40 \mathrm{mM}$ amide substrate, 6.4 and $20.1 \mathrm{mg}$ immobilised amidase and a flow rate of 0.0005 and $0.0001 \mathrm{~L} / \mathrm{min}$ respectively.

Model predictions over a range of amidase amounts and stabilities, flow rates and initial amide concentrations quantified the direction and extent of the influence of these parameters on the maximum conversions attainable, consequently identifying the critical parameter ranges defining optimal BMR performance. Although the model has been developed and validated for the prediction of BMR performance of the specific lactamide-lactic acid system,
\end{abstract}


it nevertheless has broad applicability for and relevance to broad-based prediction of the performance of immobilised enzyme BMR processes in general, irrespective of the specific enzyme or substrate moieties.

${ }^{1}$ Present address: University of Pretoria, Private Bag X20, Hatfield 0028, South Africa

Keywords: Immobilised enzyme; Biocatalytic membrane reactor; Mathematical modelling; Bioprocess 


\section{Introduction}

Biocatalytic processes frequently provide specific advantages of regio-, chemo- and enantioselectivities over chemical conversions [1, 2]. Moreover, biocatalytic processes using isolated enzymes rather than whole cells may significantly reduce the complexity of downstream processing [3]. Retention and reuse of the isolated enzymes by immobilisation in or on a matrix provide further benefit by facilitating continuous operation strategies. Membrane immobilisation has been specifically highlighted as a route to maximise process performance [4]. Membrane immobilisation techniques include ultrafiltration membranes where the enzyme is immobilised in or on the pores while the product, with a lower molecular weight relative to the enzyme, passes freely through [5]. Ultrafiltration membranes have been used successfully to retain isolated enzymes such as fumarase [3], polyphenol oxidase [6] and lipase [5]. These membranes are typically configured in flat or hollow fibre geometries in the construction of biocatalytic membrane reactors (BMRs), where substrate is fed to either the shell or lumen side, with products removed from lumen or shell side respectively.

In this study, the amidase-catalysed conversion of lactamide to lactic acid was examined and modelled in a BMR. Although soluble [7, 8] and cross-linked [9] amidase-catalysed conversions have been reported, ultrafiltration matrices have not yet been evaluated as potential immobilisation matrices. The amidase-catalysed production of lactic acid provided a model system to evaluate the process performance of an enzyme-catalysed BMR process in general and an industrially relevant process in particular. Lactic acid has various applications in the food, pharmaceutical, leather and textile industries. The world market for lactic acid is 350000 tonnes of lactic acid and this is growing by $15 \%$ annually [10]. Food-related applications account for $85 \%$ of the commercial product - as an acidulant, pH-buffering agent, flavouring agent, and bacterial inhibitor [11]. Its production by a biological-based process is economically important since this allows its being marketed as a "natural" product. A major focus of this work was the development of a mathematical model which describes the kinetic performance of an amidase-catalysed biotransformation in a BMR system and subsequent prediction of conversion performance facilitated by the model. The model was 
developed from unsteady state differential mass balances incorporating enzyme deactivation. Model accuracy was validated by comparison with experimentally determined substrate conversions under different operating conditions. The model successfully predicted the kinetics in terms of conversion over wide ranges of enzyme amounts, stability, initial substrate concentration and volumetric flow rate. Importantly, the model is not constrained to the amidase system and has broad-based value in application to BMR immobilised enzyme systems in general.

\section{Materials and methods}

\subsection{Experimental procedure for the continuous BMR}

\subsubsection{The BMR system}

The BMR comprised a borosilicate glass tubular shell (Glasschem, South Africa) with a ceramic capillary membrane insert (Tami-Industries, France) (Figure 1). The active membrane layer (molecular weight cut off $=8 \mathrm{kDa}$ ) was positioned on the lumen side. Amidase (molecular weight $=35 \mathrm{kDa}$ ), produced from Geobacillus pallidus RAPc8, cloned and over-expressed in Escherichia coli BL21 pNH 223 pLysS [12], was absorbed into the pores on the shell side. The substrate, DL-lactamide (Sigma Aldrich), 97\% purity, was fed through the shell side by means of a peristaltic pump (Vera Manostat, Sigma Aldrich). The reaction took place in the pores of the membrane, where the enzyme was immobilised, with the reaction path from the shell side to the lumen side of the BMR.

Since a major aim was to determine a fundamental kinetic relationship, it was necessary to use a single membrane to ensure that the pressure drop was uniform over the entire surface and to avoid secondary effects of the specific system geometry. An understanding of this relationship has the advantage that it can then be used to predict behaviour in more complex systems, such as increased membrane surface area.

\subsubsection{Enzyme immobilisation}

Amidase was immobilised by circulating $300 \mathrm{~mL}$ chilled enzyme solution through the shell side of the BMR at $200 \mathrm{~mL} / \mathrm{min}$ and a transmembrane pressure (TMP) of 0.5 bar (gauge) for 2 hours. The system was washed with distilled water until no enzyme protein could be 


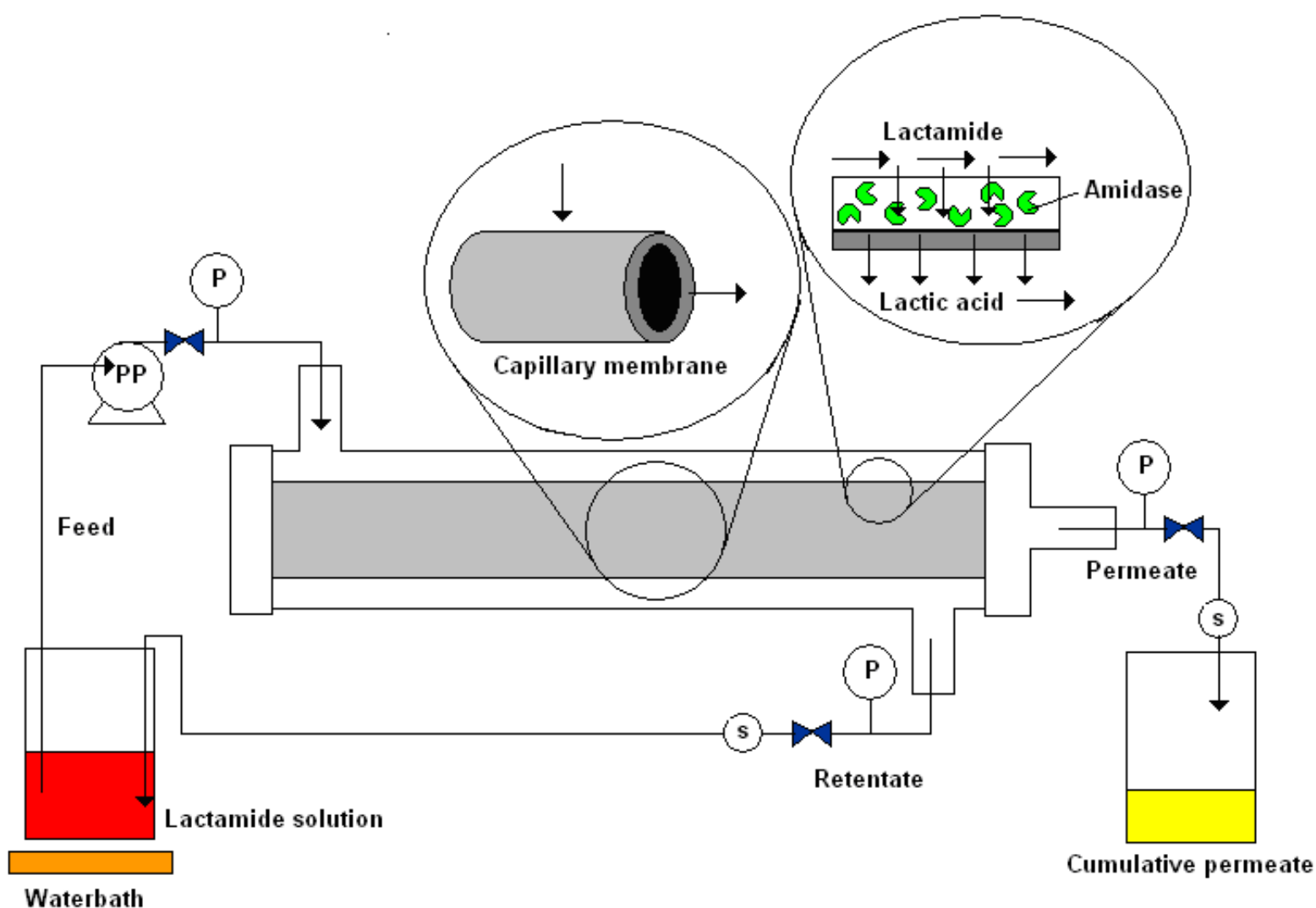

Figure 1

Schematic diagram of the membrane immobilised amidase bioreactor system ( $\mathrm{PP}=$ peristaltic pump, $\mathrm{P}=$ pressure gauge, $\mathrm{s}=$ sample point) 
detected in either the retentate or permeate streams. The amount of enzyme protein immobilised was determined from a mass balance of the residual protein in the circulating solution and the protein in the retentate and permeate washings. Effective retention of protein was confirmed since no losses occurred in the permeate or retentate streams during operation for over 20 hours after immobilisation procedures in similar experiments with different feed enzyme protein concentrations $(0.021 \mathrm{mg} / \mathrm{L}$ and $1.07 \mathrm{mg} / \mathrm{L})$.

\subsubsection{Enzyme and product analyses}

Enzyme activity was determined by quantifying the amount of ammonia released during the amidase-catalysed conversion of lactamide to lactic acid, using the phenol-hypochlorite ammonia detection method $[13,14]$. Enzyme activity was expressed in units where 1 unit was defined as the amount of amidase which catalysed the release of $1 \mu \mathrm{mol}$ of ammonia (equal to $1 \mu \mathrm{mol}$ lactic acid) per minute at standard assay conditions $\left(\mathrm{T}=50^{\circ} \mathrm{C}, \mathrm{pH}=8.0\right.$ and lactamide concentration $=80 \mathrm{mM}$ ). Specific enzyme activity was expressed in units per $\mathrm{mg}$ of enzyme protein. Enzyme protein was measured by the Bradford Coomassie Brilliant Blue dyebinding assay and the micro Bradford Coomassie Brilliant Blue dyebinding assay (Bradford Reagent, Product information, Sigma Aldrich) for protein concentrations in the ranges 50 to $1000 \mathrm{~kg} / \mathrm{mL}$ and 1 to $20 \mathrm{~kg} / \mathrm{mL}$ respectiv ely. The lactic acid product was quantified according to the amount of ammonia released (as above) since equimolar quantities of lactic acid and ammonia are formed from one mole of lactamide.

\section{Results and discussion}

\subsection{Development of the BMR system for amide conversion}

The BMR system was established for the conversion of lactamide to lactic acid using immobilised amidase as described (section 2.2.1). The parameters that define the process conditions for optimum conversion in the BMR, namely $\mathrm{pH}$, temperature, critical permeate flux and the Michaelis-Menten constant $\left(\mathrm{K}_{\mathrm{M}}\right)$, were then established prior to operation of the BMR system as follows (Sections 3.1.1 to 3.1.3).

\subsubsection{Determination of optimum $\mathrm{pH}$ and temperature}


The individual and interactive effects of the temperature and $\mathrm{pH}$ on the specific activity of amidase were determined in a two-by-two factorial design experiment. An empirical model was developed using a statistical program (A Language and Environment Copyright) to predict the amidase specific activity at different temperatures and $\mathrm{pH}$ 's (Equation 1). The model predictions were compared with experimental data at pH's of $6.0,7.0,8.0$ and 8.5, each at temperatures of $40^{\circ} \mathrm{C}, 50^{\circ} \mathrm{C}, 60^{\circ} \mathrm{C}$ and $70^{\circ} \mathrm{C}$. Correlation coefficients indicated a good fit to the experimental data. (For example, the correlation coefficient for the variation of specific activity at $50^{\circ} \mathrm{C}$ at $7.0<\mathrm{pH}<8.5$ and at $\mathrm{pH} 8.0$ at $40^{\circ} \mathrm{C}<$ temperature $<70^{\circ} \mathrm{C}$ was 0.97.) Statistical verification of the model was affirmed by determining that the residuals have homogenous variances and that they follow a normal distribution around a zero point. The statistically verified model was then used to predict the $\mathrm{pH}$ and temperature at which the enzyme exhibited the highest activity. A graphical representation of the model (Figure 2) shows an optimum temperature and $\mathrm{pH}$ in the ranges of $50^{\circ} \mathrm{C}$ to $60^{\circ} \mathrm{C}$ and 7.5 to 8.5 respectively. Accordingly, a temperature of $50^{\circ} \mathrm{C}$ and $\mathrm{pH} 8$ was used throughout the experimental work. The difference in performance between $50^{\circ} \mathrm{C}$ and $60^{\circ} \mathrm{C}$ was negligible and in the interest of energy conservation, the lower temperature was chosen.

Specific activity $=0.191(\pi)+1.71 \mathrm{pH})-0.00183\left(\pi^{\mathcal{P}}-0.109 \mathrm{kH} \mathcal{f}-10.39\right.$

\subsubsection{Determination of critical permeate flux}

The critical permeate flux for $80 \mathrm{mM}$ lactamide was determined prior to immobilization. (The critical permeate flux is the lowest flux which will not significantly increase with an increase in TMP). The permeate flux was measured at TMPs over the range 0 to 2.2 bar (gauge), yielding a critical flux at approximately 2 bar (flow rate of $0.055 \mathrm{~L} / \mathrm{min}$ ). A permeate flux below the critical flux was used in all of the experiments in order to prevent permanent fouling of the membrane. In addition, pure water permeability (flux/TMP) was determined after each experiment to confirm that no fouling occurred during the period of experimentation.

\subsubsection{Determination of the free enzyme $K_{M}$}

The Michaelis-Menten constant, $\mathrm{K}_{\mathrm{M}}$, of the free enzyme was determined as $68 \mathrm{mM}$ via nonlinear regression of initial rate data using free amidase. Initial rates were obtained from the 


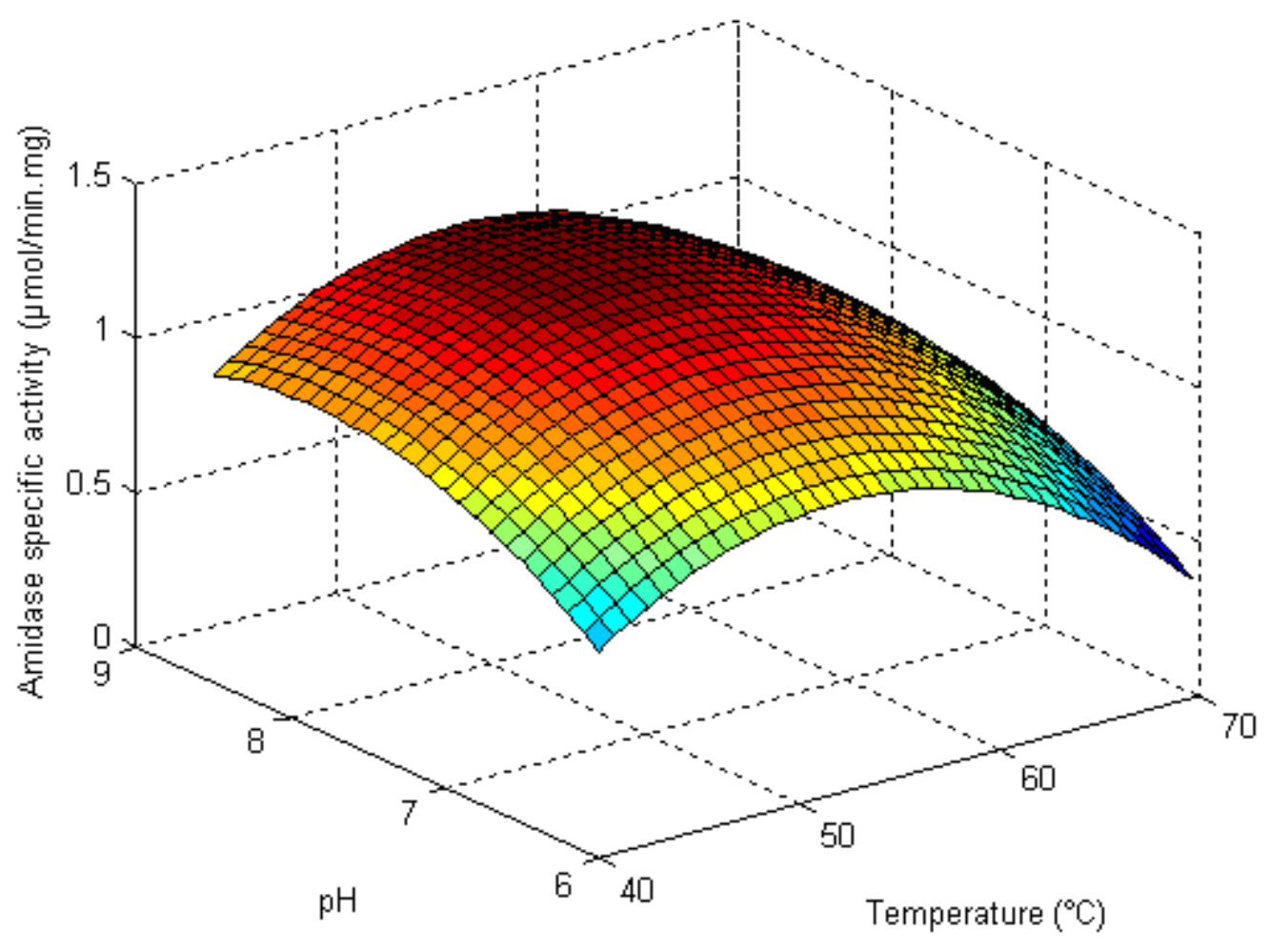

Figure 2

Cumulative effect of $\mathrm{pH}$ and temperature on the amidase specific activity as predicted by Equation 1 
rate of increase in lactic acid for the first 6 minutes of the conversion of lactamide at the optimum $\mathrm{pH}$ and temperature $\left(\mathrm{pH}=8.0,50^{\circ} \mathrm{C}\right)$ and $1 \mathrm{mg}$ of enzyme protein, for lactamide concentrations $15 \mathrm{mM}, 40 \mathrm{mM}, 60 \mathrm{mM}, 80 \mathrm{mM}, 100 \mathrm{mM}$ and $150 \mathrm{mM}$.

\subsection{Conversion in the BMR}

Conversions of lactamide to lactic acid in the BMR were conducted in two experiments with different substrate and initial enzyme concentrations and flow rates. Conditions were as follows: substrate $80 \mathrm{mmol} / \mathrm{L}$, enzyme $6.38 \mathrm{mg}$, flow rate $0.0005 \mathrm{~L} / \mathrm{min}$ (experiment 1) and substrate $40 \mathrm{mmol} / \mathrm{L}$, enzyme $20.09 \mathrm{mg}$, flow rate $0.0001 \mathrm{~L} / \mathrm{min}$ (experiment 2). The experiments in the BMR were conducted at the optimum $\mathrm{pH}$ and temperature $(\mathrm{pH}=8.0$, $\left.50^{\circ} \mathrm{C}\right)$ and below the critical flux.

The conversion of substrate to product was determined in each experiment at discrete time intervals from the fractional substrate utilisation (Equation 2), where $\mathrm{X}$ represents conversion and $\mathrm{C}$ represents concentration. Subscripts $\mathrm{S}$ and 0 represent the substrate and initial value respectively.

$$
\underline{X=\frac{c_{S 0}-c_{S}}{c_{S 0}}}
$$

These experimentally derived conversions were determined for later comparison with the conversions predicted by the mathematical model developed below (section 3.3).

Low conversion was obtained, partly due to the low enzyme functional stability. The conversion can be enhanced by increasing the membrane area (as discussed in Section 2.2.1) and/ or by improving the enzyme stability. Nevertheless, a low conversion is desired when developing a kinetic relationship as the resulting low product concentration means that secondary reactions and the reverse reaction are avoided, leading to a more accurate expression.

\subsection{Development of a model to predict conversion in the BMR}

A mathematical model was developed from first principles to predict the conversion kinetics in the BMR. The development of a mathematical model has an important consequence in that the model facilitates prediction of conversion in the BMR outside of the prevailing experimental constraints. In this way, quantification of the conversion kinetics may be 
successfully extended to describe the dependence of conversion on a wide range on process conditions, and further, to do this without the need for additional experimentation.

For the model development, the reaction zone was assumed to be represented by a continuously stirred tank reactor (CSTR) operating at unsteady state. The unsteady state assumption was necessary since the enzyme decayed with time. The CSTR assumption is valid when the retentate to permeate recycle ratio is larger than 100 [15], 4 to 20 times less than in the study presented here.

A standard mole balance to account for the change in substrate in the CSTR with time was used (Equation 3), where $\mathrm{N}$ is the number of moles, $\mathrm{F}$ is the molar flow rate, $\mathrm{V}$ is the reaction volume (the volume of the micropores in the membrane, supplied by Tami Industries, France) and $r$ is the reaction rate.

$$
\frac{d N_{S}}{d t}=F_{S O}-F_{S}-r_{S} \cdot V
$$

Given that the reaction volume and volumetric flow rate $(v)$ are constant, and using the definition of conversion in Equation 2, Equation 3 may be modified to Equation 4.

$$
\frac{d X}{d t}=\frac{r_{S}}{c_{S o}}-\frac{v x}{V}
$$

The predicted conversion vs. time function can then be obtained by solving Equation 4 using the standard $4^{\text {th }}$ order Runge-Kutta method.

As a first approximation, the reaction was assumed to follow Michaelis-Menten kinetics with the reaction rate accordingly given by Equation 5 , where $\mathrm{K}_{\mathrm{M}}$ is the Michaelis-Menten constant with a maximum rate of reaction $\left(r_{\max }\right)$ proportional to the enzyme activity $\left(e_{a}\right)$ as in Equation 6.

$$
\begin{aligned}
& r_{S}=\frac{r_{\max } C_{S}}{c_{S}+K_{M}} \\
& r_{\max }=k_{3} \cdot e_{a}
\end{aligned}
$$

However, this reaction rate will change continuously due to the decay in enzyme activity with time. This decay in enzyme activity can be described by one of several decay laws, where the appropriate decay law is determined by the best fit of experimental data. The 
experimental fit using a first order (Section 3.3.1) and a second order decay law (Section 3.3.2) have been evaluated and compared.

\subsubsection{Model with first order enzyme decay law}

A first order decay law, which is standardly employed in most models of enzyme decay, was evaluated initially. The first order decay law is shown in Equation 7, where $k_{d}$ is the decay constant and $\mathrm{a}$ is the fraction of enzyme activity remaining at a particular time, relative to the initial activity, according to Equation 8.

$$
\begin{aligned}
& \frac{d a}{d t}=-k_{d} a \\
& e_{a}=e_{a 0} \cdot a
\end{aligned}
$$

Integration of Equation 7 and substitution into Equation 8 gives the residual enzyme activity at any time (Equation 9).

$$
e_{a}=e_{a 0} \cdot \exp \left[-k_{d} \cdot t\right]
$$

The constants $\mathrm{K}_{\mathrm{M}}, \mathrm{K}_{3}$ and $\mathrm{k}_{d}$ (inherent in the rate expression (Equation 5)) were determined by varying the values of these parameters until the predicted conversion vs. time curve best represented the experimentally determined data. This was carried out using multidimensional unconstrained nonlinear minimization, Nelder-Mead in MATLAB ${ }^{\mathrm{TM}}$, to minimise the difference between the predicted and experimental conversion data.

The conversion predicted by the model incorporating the first order enzyme decay was then superimposed on experimental data obtained at two different experimental conditions viz. 80 and $40 \mathrm{mM}$ substrate, 6.38 and $20.09 \mathrm{mg}$ immobilised enzyme, $5 \times 10^{-4}$ and $10^{-4} \mathrm{~L} / \mathrm{min}$ flow rate for experiments 1 and 2 respectively (Figure 3). The maximum (peak) conversions, $X_{\max }$, of approximately 0.02 (experiment 1 ) and 0.035 (experiment 2) were obtained around 200 $\min$.

However, although the predicted curves fit most of the data well, the conversion at long run time was underestimated. This could indicate either that mass transfer limitation was actually significant or alternatively, that the enzyme deactivation did not follow a first order decay law. This is elucidated in section 3.3.2 below.

\subsubsection{Model with second order enzyme decay law}




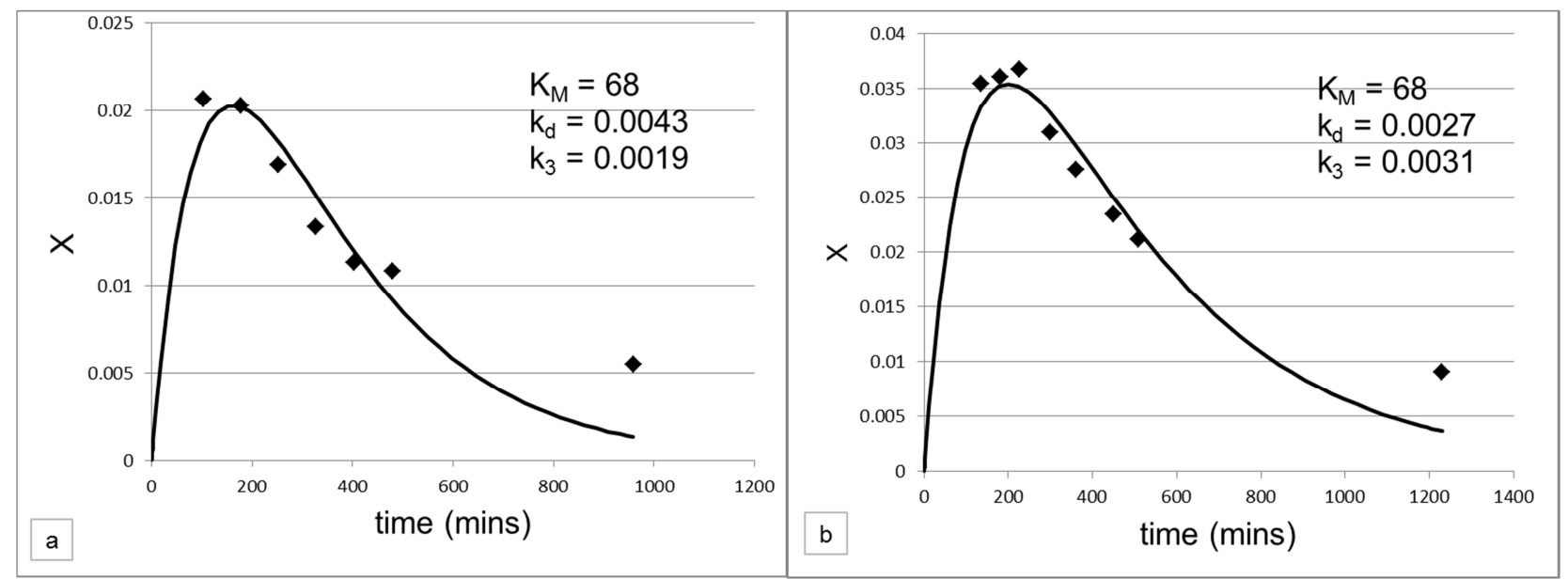

\section{Figure 3}

First order decay model fit to experimental data in (a) experiment $1\left(\mathrm{C}_{\mathrm{s} 0}=80 \mathrm{mmol} / \mathrm{dm}^{3} ; \mathrm{e}_{\mathrm{a} 0}=6.38 \mathrm{mg} ; \mathrm{v}=0.0005\right.$ $\mathrm{L} / \mathrm{min}$ ) and (b) experiment 2 (b) $\left(\mathrm{C}_{\mathrm{S}_{0}}=40 \mathrm{mmol} / \mathrm{dm}^{3} ; \mathrm{e}_{\mathrm{a} 0}=20.09 \mathrm{mg} ; \mathrm{v}=0.0001 \mathrm{~L} / \mathrm{min}\right)$

Figure 4 
An alternative enzyme decay law which involves a second order change in enzyme activity with time (Equation 10) was subsequently investigated.

$$
\frac{d a}{d t}=-k_{d} a^{2}
$$

Integration of Equation 10 and substitution into Equation 8 for enzyme activity gives the amount of residual enzyme activity at any time (Equation 11). Equation 11 thus replaces Equation 9 with the remaining equations unchanged.

$$
e_{a}=e_{a 0} \cdot a=e_{a 0} \cdot \frac{1}{k_{d \cdot t+1}}
$$

This model exhibited a good fit to the experimentally determined data in experiment 1 and experiment 2 (Figure 4), superior to the previous model which was developed using the standard first order enzyme decay. Moreover, the value of the calculated $K_{M}$ was the same as that determined with free cell kinetics for both experiments. These results demonstrate that the model incorporating a second order enzyme decay more accurately represents the actual system. Hence the observed deviation of conversion at long times observed when using a first order decay model (Figure 3b) was in fact a consequence of an inadequate expression for enzyme decay and not a result of mass transfer limitation of observed kinetics in the membrane support of the BMR.

\subsubsection{Validation of mass transfer exclusion}

To confirm that mass transfer in the membrane support did not limit the observed reaction rate, an effectiveness factor ( $\eta$ ) was determined. An accepted method for accounting for mass transfer within a porous structure is to include an effectiveness factor into the rate expression, similar to that employed in heterogeneous catalytic systems [16], to account for the percentage effective activity of the enzyme. The rate equation (Equation 5) then becomes Equation 12:

$$
r_{S}=\eta \frac{r_{\max } C_{S}}{C_{s}+K_{M}}
$$

The effectiveness factor is calculated from the Thiele modulus $\left(\phi_{1}\right)$. The relationship between the effectiveness factor and the Thiele modulus is given in Equation 13 [16, 17]. 

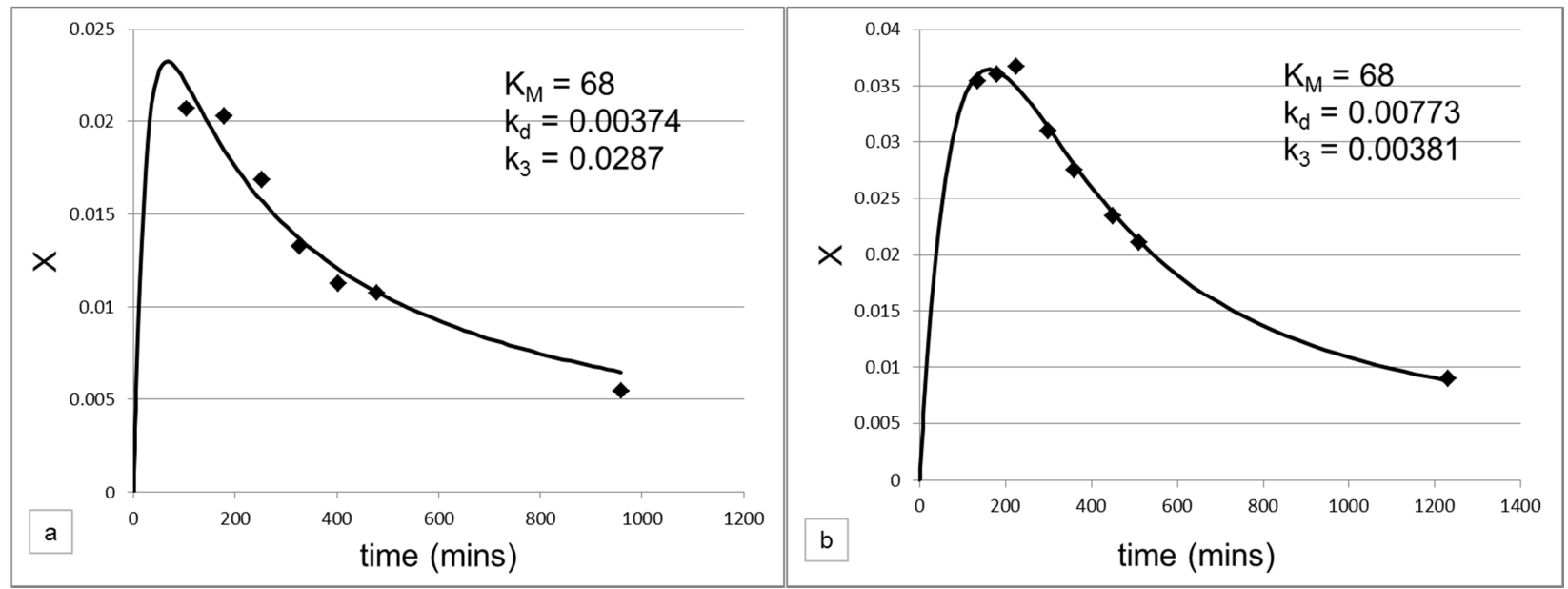

\section{Figure 4}

Second order decay model fit to experimental data in (a) experiment $1\left(C_{s_{0}}=80 \mathrm{mmol} / \mathrm{dm}^{3} ; e_{a 0}=6.38\right.$ $\mathrm{mg} ; \mathrm{v}=0.0005 \mathrm{~L} / \mathrm{min})$ and $(\mathrm{b})$ experiment 2 (b) $\left(\mathrm{C}_{\mathrm{s} 0}=40 \mathrm{mmol} / \mathrm{dm}^{3} ; \mathrm{e}_{\mathrm{a} 0}=20.09 \mathrm{mg} ; \mathrm{v}=0.0001 \mathrm{~L} / \mathrm{min}\right)$ 


$$
\eta=\frac{3}{\phi_{1}}\left(\frac{1}{\tanh \phi_{1}}-\frac{1}{\phi_{1}}\right)
$$

The Thiele modulus is calculated from Equation 14 [16], where $L$ is the membrane thickness $(0.002 \mathrm{~m}), \mathrm{k}_{1}$ is the first order rate constant and $D_{e}$ is the effective diffusivity. Equation 14 is valid because, although the configuration of the membrane is cylindrical, the relative dimensions mean that the system can be treated as diffusion to a flat plate.

$$
\phi_{1}=L \sqrt{\frac{k_{1} / D_{e}}{D_{e}}}
$$

As the reaction is not first order, an estimate of $k_{1}$ needs to be made. This is done using the form of the rate equation which excludes the effectiveness factor (Equation 15).

$$
\begin{aligned}
& r_{S}=\frac{r_{\max } C_{S}}{c_{S}+K_{M}} \approx k_{1} \cdot C_{S} \\
& \text { where } k_{1} \approx \frac{r_{\max }}{C_{S}+K_{M}}
\end{aligned}
$$

Equation 16 may be further simplified to Equation 17 by realising that the value of the substrate concentration is approximately constant over the range of data gathered, due to the overall low conversion obtained. Hence, $\mathrm{k}_{1}$ becomes a constant.

$$
k_{1} \approx \frac{r_{\max }}{C_{S 0}+K_{M}}
$$

It may be assumed that diffusion in the membrane occurs only via the mode of bulk-phase diffusion, which is a reasonable assumption, given the large pore diameter of the membrane. The effective diffusivity $\left(D_{e}\right)$ may, therefore, be estimated using the Hayduk-Laudie correlation for infinite dilution on non-electrolytes in water [18] as $5.38 \times 10^{-8} \mathrm{~m}^{2} / \mathrm{min}$.

The effectiveness factors for the two experiments were calculated from Equation 13 using the values determined during modelling, as listed in Table 1. At the initial conditions used in the rate equation, the rate will be fastest and, therefore, if there are mass transfer limitations, they should be the most severe. The effectiveness factors for both experiment 1 and 2 are close to unity, thereby confirming that mass transfer limitations have no effect on the process under investigation and therefore, that mass transfer limitation need not be incorporated into the model equations.

\subsection{Model predictions}




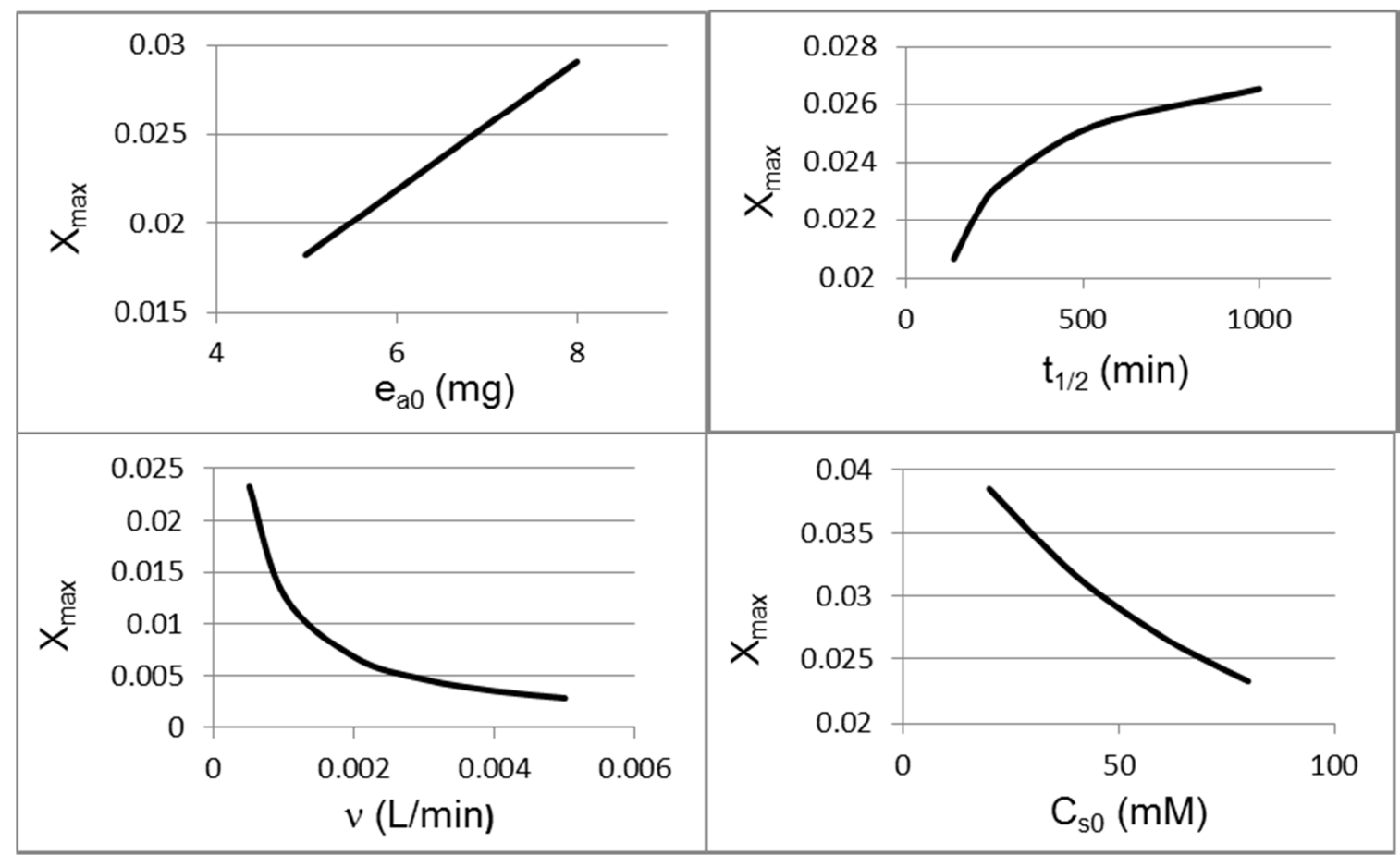

Figure 5

Sensitivity analysis 
The model predicting conversion in a BMR, incorporating a second order enzyme decay, was therefore validated, allowing for its use as a vehicle to predict conversion performance in the BMR system under hypothetical process conditions outside of the conditions imposed during the actual experimentation. Consequently, model predictions of conversion were calculated over a range of amidase amounts (5-8 mg), amidase stabilities (134-1000 min half-life), volumetric flow rates $(0.001-0.005 \mathrm{~L} / \mathrm{min})$ and initial substrate concentrations $(20-80 \mathrm{mM})$. This facilitated a sensitivity analysis where the magnitude of the influences of changes in these parameters on BMR conversion could be quantified and compared (Figure 5).

An increase in the amount of immobilised amidase from 5 to $8 \mathrm{mg}$ led to a proportional 1.6fold increase in the maximum conversion from $18 \%$ to $29 \%$. Similarly, an increase in the amidase stability enhanced the maximum conversion, as demonstrated by a 1.3-fold increase as the half-life increased from 134 to $1000 \mathrm{~h}$.

An increase in the volumetric flow rate from 0.0005 to $0.002 \mathrm{~L} / \mathrm{min}$ resulted in a sharp 3.5fold decrease in the maximum conversion as a result of the decreased residence time of the substrate in the membrane. Flow rates above $0.002 \mathrm{~L} / \mathrm{min}$, however, had less effect on the conversion since the residence times were all so low that the rate of passage of substrate through the membrane was too high for significant contact between the substrate and enzyme molecules. This suggests operation at a flow rate below $0.002 \mathrm{~L} / \mathrm{min}$ in this system is advisable if conversion is to be maximised. An additional constraint to the maximum flow rate is the possibility of enzyme denaturation above a threshold flux.

An increase in the substrate concentration resulted in a decrease in the maximum conversion, levelling off at high concentrations. This is in accordance with Michaelis-Menten kinetics. At high substrate concentrations when most of the active sites of the enzyme molecules are already saturated, further increases in the substrate concentration are unlikely to result in a significant increase in the reaction rate.

\section{Conclusions}

A BMR system was successfully developed for the enzymatic conversion of amide to acid via an amidase-catalysed reaction using the lactamide to lactic acid conversion as a 
representative system. The amidase was immobilised in the pores of a ceramic membrane with substrate flow from the shell to lumen side and collection of the product in the permeate stream. Conversions were empirically determined in this system under optimum $\mathrm{pH}$ and temperature conditions and discrete amidase amounts, amidase stabilities, volumetric flow rates and initial substrate concentrations.

An unsteady state mathematical model incorporating a second order enzyme decay was developed from first principles. The model was rigorously validated against the experimental data obtained and its accuracy in predicting conversion confirmed. The possibility of mass transfer limitation was eliminated and intrinsic kinetic control was established. The validated model facilitated a sensitivity analysis which quantified the BMR performance in terms of the influences of critical process parameters on conversion over a wide range of hypothetical process conditions extending beyond the experimental constraints. Specifically, the changes in the maximum conversions attainable associated with alterations in the amidase amount and stability, as well as those associated with operational changes in flow rates and initial substrate concentrations, have been quantified. These results establish the importance of the amidase activity and stability and the judicious choice of volumetric flow rate and initial substrate concentration in optimising BMR performance. Most importantly, they demonstrate the capability of the model to quantify the extent of the influence of the amount and stability of the amidase on the process performance and inform on process parameters which define optimum performance.

Although the mathematical model has been developed and validated for the amidase catalysed conversion of lactamide to lactic acid in the BMR system in this study, the model is not specific to this system and can be used to similarly in other immobilised enzyme catalysed conversions in a BMR under conditions where mass transfer limitation is not significant. Consequently, a major strength of this model is that, while it has been developed and validated for the prediction of performance parameters of a specific reaction system, it nevertheless has applicability for and relevance to broad-based prediction of the performance of immobilised enzyme BMR processes in general. Consequently it could be 
useful to apply it to data from systems which report similar immobilised enzyme membrane reactor configurations in the literature.

\section{Acknowledgements}

This work is based on research supported by the National Research Foundation (NRF), South Africa (SA). The authors gratefully acknowledge funding from the NRF and Stellenbosch University, SA. R du Preez acknowledges bursary funding from the NRF. DA Cowan (previously University of the Western Cape, SA, now University of Pretoria, SA) is thanked for permission to use his cloned amidase and SG Burton (previously University of Cape Town, SA, now University of Pretoria, SA) and STL Harrison (University of Cape Town, SA) for supply of the amidase.

\section{References}

[1] S.F. D’Souza, Current Science 77 (1999) 69-79.

[2] S.M. Thomas, R. DiCosimo, V. Nagarajan, Trends Biotechnol. 20 (2002) 238-242.

[3] L. Giorno, E. Drioli, G. Carvoli, A. Cassano, L. Donato, Biotechnol. Bioeng. 72 (2000) 77-84.

[4] H. Velankar, K.G. Clarke, R. du Preez, D. Cowan, S.G. Burton, Trends Biotechnol. 28 (2010) 561-569.

[5] L. Giorno, E. Drioli, Trends Biotechnol. 18 (2000) 339-349.

[6] A. Boshoff, W. Edwards, W.D. Leukes, P.D. Rose, S.G. Burton, Desalination 115 (1998) 307-312.

[7] S. Kim, P. Oriel, Enzyme Microbial. Technol. 27 (2000) 492-501.

[8] M.M. Tauber, A. Cavaco-Paulo, K.H. Robra, G.M. Gubitz, Appl. Environ. Microbiol. 66 (2000) 1634-1638.

[9] D. Kubáč, A. Cejkova, J. Masak, V. Jirku, M. Lemaine, E. Gallienne, J. Bolte, R. Stloukal, L. Martinkova, J. Mol. Catal. B: Enzym. 39 (2006) 59-61.

[10] K.L. Wasewar, A.B.M. Heesink, G.F. Versteeg, V.G. Pangarkar, Chem. Eng. Sci. 59, (2004) 2315-2320.

[11] N. Narayanan, P.K. Roychoudhury, A. Srivastava, J. Biotechnol. 7(2) (2004), 167-179. 
[12] R.A. Cameron, M. Sayed, D.A. Cowan, Biochem. Biophys. Acta 1725 (2005) 35-46.

[13] R.A. Pereira, D. Graham, F.A. Rainey, D.A. Cowan, Extremophiles 2 (1998) 347-357.

[14] M.W. Weatherburn, Anal. Chem. (1967) 39 971-974.

[15] C.M.L. Carvalho, M.R. Aires-Barros, J.M.S. Cabral, Biotechnol. Bioeng. 72 (2001) 2, $127-135$.

[16] H.S. Fogler, Elements of Chemical Reaction Engineering, fourth ed., Prentice Hall, 2006.

[17] O. Levenspiel, Chemical Reaction Engineering, third ed, John Wiley \& Sons, 1999.

[18] H. Perry, D. Green, Perry's Chemical Engineers' Handbook, eleventh ed., McGraw Hill, 1997. 